\title{
Epidemiología del COVID-19 en América Latina
}

\author{
Covid-19 epidemiology in Latin America \\ Nancy Doris Calzada-Gonzales ${ }^{1, a *}$, Maribel Jessica Calzada-Gonzales 2,a
}

Filiación y grado académico

Clínica Odontológica Nueva Imagen - Huánuco,

Perú.

2 Universidad de Huánuco, Perú.

a Doctora en Ciencias de la Salud.

D. ORCID iD de Nancy Calzada-Gonzales https://orcid.org/0000-0001-5179-3790

(D) ORCID iD de Maribel Calzada-Gonzales https://orcid.org/0000-0003-4524-4984

Contribución de los autores

NC: ejecución de la investigación y elaboración del artículo.

MC: recolección de la información y elaboración del artículo.

Fuentes de financiamiento

Autofinanciado.

Conflictos de interés

Los autores declaran no tener conflictos de interés en la publicación de este artículo.

Recibido: 18-04-2020

Arbitrado por pares

Aceptado: 15-05-2020

Citar como

Calzada-Gonzales N, Calzada-Gonzales M. Epidemiología del COVID-19 en américa latina. Rev Peru Cienc Salud. 2020; 2 (2): 102-8. doi: https://doi.org/10.37711/rpcs.2020.2.2.126

Correspondencia

Dra. Nancy Doris, Calzada-Gonzales

Dirección: Jr. Independencia 1321

Cel.: 975838361

Email: nancycalzadag@hotmail.com

\section{RESUMEN}

El síndrome respiratorio agudo severo (SRAS), es causado por el coronavirus (SARS-CoV-2); este utiliza el receptor de la enzima convertidora de angiotensina 2 (ACE2), para invadir los cuerpos humanos. En diciembre de 2019 surgió un brote sin precedentes de neumonía de etiología desconocida en la ciudad de Wuhan, provincia de Hubei en China. El brote se informó a la OMS el 31 de diciembre de 2019, quien el 11 de febrero lo denominó COVID-19. América Latina no fue la excepción a este problema de salud pública: el 25 de febrero de 2020, el Ministerio de Salud de Brasil confirmó el primer caso confirmado un hombre brasileño, de 61 años. Actualmente, pese a los rigurosos esfuerzos globales de contención y cuarentena, la incidencia de COVID-19 continúa aumentando, con 3435894 casos confirmados por laboratorio y más de 239000 muertes en todo el mundo. En respuesta a este brote global, realizaremos una revisión, de la epidemiología a nivel de América Latina.

Palabras clave: de edad mediana, síndrome respiratorio agudo severo, COVID-19, coronavirus, cuarentena, enzima convertidora de angiotensina 2, Peptidil-dipeptidasa A., America latina, salud pública, cuerpo humano, síndrome respiratorio agudo severo, infecciones por coronavirus, China, brotes de enfermedades, neumonía (Fuente: DeCS - BIREME).

\section{ABSTRACT}

Severe acute respiratory syndrome (SARS), is caused by coronavirus (SARSCoV-2). It uses the angiotensin-converting enzyme 2 receptor (ACE2) to invade human bodies. In December 2019, an unprecedented outbreak of pneumonia of unknown etiology emerged in Wuhan City, Hubei Province of China. The outbreak was reported to the WHO on December 31, 2019, who on February 11 named it COVID-19. Latin America was no exception to this public health problem. On February 25, 2020, the Brazilian Department of Health confirmed the first confirmed case of a 61-year-old Brazilian man. Currently, despite rigorous global containment and quarantine efforts, the incidence of COVID-19 continues to rise, with 3,435,894 laboratory confirmed cases and more than 239,000 deaths worldwide. In response to this global outbreak, we will conduct an epidemiology review regarding Latin American.

Keywords: severe acute respiratory syndrome, COVID-19, coronavirus, quarantine, angiotensin converting enzyme 2, Peptidyl dipeptidase A., Latin America, public health, human body, severe acute respiratory syndrome, coronavirus infections, China, disease outbreaks, pneumonia (Source: $\mathrm{MeSH}$ NLM). 


\section{INTRODUCCIÓN}

El coronavirus es uno de los principales patógenos que se dirige principalmente al sistema respiratorio humano. Los brotes previos de coronavirus ( $\mathrm{CoV}$ ) incluyen el síndrome respiratorio agudo severo (SARS) - CoV y el síndrome respiratorio del Medio Oriente (MERS) -CoV, que se han caracterizado previamente por representar una gran amenaza para la salud pública. Con respecto al virus en sí, el Comité Internacional de Taxonomía de Virus ha renombrado al nombrado anteriormente de manera provisional, 2019-nCoV, como coronavirus-2 (SARS-CoV-2) del síndrome respiratorio agudo severo ${ }^{(1)}$.

La epidemia de infección aguda desconocida del tracto respiratorio estalló primero en Wuhan, China, desde el 12 de diciembre de 2019, posiblemente relacionada con un mercado de mariscos. Varios estudios sugirieron que el murciélago puede ser el reservorio potencial de SARS-CoV-2 ${ }^{(2,3)}$. El 30 de enero de 2020, la OMS declaró que el brote chino de COVID-19 era una emergencia de salud pública de preocupación internacional que presentaba un alto riesgo para los países con sistemas de salud vulnerables. El 11 de febrero, de acuerdo a la explicación de la OMS, el nuevo nombre se toma de las palabras "corona", "virus" y disease (enfermedad en inglés), mientras que 19 representa el año en que surgió (el brote se informó a la OMS el 31 de diciembre de 2019).

En América Latina el primer caso fue reportado en Brasil, el 25 de febrero de 2020. Este primer caso fue un hombre brasileño, de 61 años, que viajó del 9 al 20 de febrero de 2020 a Lombardía, en el norte de Italia, donde se está produciendo un brote significativo ${ }^{(4)}$. El paciente presentó fiebre, tos seca, dolor de garganta y coriza, recibió atención preventiva estándar y, mientras tanto, está aislado en su hogar ${ }^{(5)}$. Este es el primer caso de COVID-19 en la región de América del Sur que alberga una población de más de 640 millones de personas ${ }^{(6)}$.

México fue el segundo país que reportó su primer caso por COVID-19, el 27 de febrero. Se trató de un mexicano que viajó a Italia. El tercer país que reportó el brote epidémico fue Ecuador; una mujer de 71 años de edad quien regresaba de España. Después de 22 días de reportado el primer caso de coronavirus en América Latina, El Salvador y Nicaragua informaron de sus primeros casos contagiados, siendo los últimos países en confirmar.

El 11 de marzo, el director general de la Organización Mundial de la Salud (OMS), Tedros Adhanom Ghebreyesus, declaró que el coronavirus Covid-19 pasaba de ser una epidemia a una pandemia. Decisión tomada por la creciente propagación del virus por todo el mundo. Que para esa fecha hubo más de 118000 casos confirmados en 114 países y regiones y 4291 personas han perdido la vida. Las acciones generadas debido a la pandemia por los países de América Latina fueron: cuarentena, toque de queda, aislamiento voluntario y aislamiento obligatorio.

A nivel mundial, la primera cuarentena directa por la pandemia de COVID-19 fue en la República Popular China, cuando el gobierno ordenó el encierro de la provincia de Hubei, el 23 de enero de 2020, que incluía a Wuhan, ciudad en donde apareció el SARS-CoV-2 que origina la enfermedad. Mientras que en América Latina, El Salvador y Paraguay fueron los países que iniciaron con la orden de cuarentena, el 11 de marzo, inclusive sin casos confirmados por COVID-19.

\section{DESARROLLO DEL TEMA}

\section{Historia}

En los últimos 17 años ocurrieron dos epidemias generalizadas de síndrome respiratorio agudo severo (SRAS) en China, que fueron causadas por coronavirus relacionados (CoV): SARS-CoV y SARS-CoV-2. Aunque los orígenes de estos virus aún son desconocidos y sus ocurrencias en la naturaleza son misteriosas, algunos patrones generales de su patogénesis y epidemias son notables. Ambos virus utilizan el mismo receptor, la enzima convertidora de angiotensina 2 (ACE2), para invadir los cuerpos humanos. Ambas epidemias ocurrieron en temporadas frías y secas de invierno con baja humedad; las cuales podrían proporcionar las condiciones ambientales propicias para una supervivencia viral ${ }^{(7)}$.

Lu et al ${ }^{(8)}$ el 31 de diciembre de 2019, se identificaron 27 casos de neumonía de etiología desconocida en la ciudad de Wuhan, provincia de Hubei en China ${ }^{(8)}$. Wuhan es la ciudad más poblada del centro de China con una población que supera los 11 millones. Estos pacientes presentaron síntomas clínicos de tos seca, disnea, fiebre e infiltrados pulmonares bilaterales en las imágenes. Todos los casos estaban relacionados con el mercado mayorista de mariscos Huanan de Wuhan, que comercializa pescado y una variedad de especies de animales vivos, como aves de corral, murciélagos, marmotas y serpientes.

El agente causal se identificó a partir de muestras de hisopos de garganta realizadas por el Centro Chino para el Control y la Prevención de Enfermedades (CCDC), el 7 de enero de 2020, y posteriormente se denominó 
Coronavirus 2 del Síndrome Respiratorio Agudo Severo (SARS-CoV-2). La enfermedad fue finalmente nombrada COVID-19 por la Organización Mundial de la Salud (OMS) ${ }^{(9)}$.

\section{Origen y transmisión}

EI SARS-CoV-2 es un coronavirus $\beta$, que está envuelto en un virus de ARN de sentido positivo no segmentado (sarbecovirus subgénero, subfamilia Orthocoronavirinae) ${ }^{(10)}$. Los coronavirus (CoV) se dividen en cuatro géneros, incluidos $\alpha-/ \beta-/ \gamma-/ \delta$-CoV. $\alpha-y \beta-C o V$ pueden infectar a los mamíferos, mientras que $\gamma$ - y $\delta$-CoV tienden a infectar a las aves. Los otros dos $\beta$-CoV conocidos, SARS-CoV y MERS-CoV conducen a infecciones respiratorias graves y potencialmente fatales ${ }^{(11)}$. Se descubrió que la secuencia del genoma del SARS-CoV-2 es idéntica en un $96.2 \%$ a un RaVG13 de CoV de murciélago, mientras que comparte una identidad del 79,5\% con el SARS-CoV. Según los resultados de la secuenciación del genoma del virus y el análisis evolutivo, se sospecha que el murciélago es el huésped natural del origen del virus, y el SARS-CoV-2 podría transmitirse desde los murciélagos a través de huéspedes intermedios desconocidos para infectar a los humanos. Ahora está claro que el SARS-CoV-2 podría usar la enzima convertidora de angiotensina 2 (ACE2), el mismo receptor que el SARS-CoV, para infectar a los humanos ${ }^{(12)}$.

\section{Sintomatología}

Los síntomas de la infección por COVID-19 aparecen después de un período de incubación de aproximadamente 5.2 días $^{(13)}$. El período desde el inicio de los síntomas de COVID-19 hasta la muerte osciló entre 6 y 41 días, con una mediana de 14 días ${ }^{(14)}$. Este período depende de la edad del paciente y del estado del sistema inmunitario del paciente. Fue más corto entre los pacientes mayores de 70 años en comparación con los menores de 70 años ${ }^{(14)}$. Los síntomas más comunes al comienzo de la enfermedad de COVID-19 son fiebre, tos y fatiga, mientras que otros síntomas incluyen producción de esputo, dolor de cabeza, hemoptisis, diarrea, disnea y linfopenia ${ }^{(14-16)}$.

Las tomografías computarizadas de tórax de todos los pacientes que padecían neumonía, mostraron sombras en el pulmón ${ }^{(17)}$. En las primeras etapas de la enfermedad, los pacientes presentan múltiples sombras de parches pequeños y cambios intersticiales, especialmente en la zona extrapulmonar. Progresa aún más a múltiples de opacidades de vidrio esmerilado periférico en regiones subpleurales de ambos pulmones ${ }^{(18)}$; lo que probablemente induce a una respuesta inmune tanto sistémica como localizada que condujo a un aumento de la inflamación.

\section{Coronavirus en el mundo}

El 3 de mayo del 2020, ya son más tres millones de casos de coronavirus en el mundo y casi 239604 muertos Los datos sobre gravedad de los casos confirmados han ido variando a lo largo del tiempo; lo cual es frecuente durante los brotes de enfermedades emergentes, en los que inicialmente se detectan los casos más graves y a medida que evoluciona se identifican casos más leves. Estados Unidos es el país con más casos de coronavirus reportados, por encima de China, Italia y España. Hay al menos 1125719 casos de coronavirus registrados en Estados Unidos, según el recuento de CNN Health a través de los sistemas de salud pública.

\section{En Asia}

El origen de la pandemia fue en Wuhan (China), por COVID-19. Los primeros casos se informaron en diciembre de $2019^{(19)}$ y luego se extendió a otras áreas en China continental. La OMS ha denominado oficialmente la enfermedad COVID-19 ${ }^{(20)}$. Desde el 18 de diciembre de 2019 hasta el 29 de diciembre de 2019, cinco pacientes fueron hospitalizados con síndrome de dificultad respiratoria aguda, habiendo fallecido uno de los mismos ${ }^{(15)}$. Para el 2 de enero de 2020, 41 pacientes fueron hospitalizados, siendo identificados como infectados por COVID-19 confirmados por laboratorio; menos de la mitad de estos pacientes tenían enfermedades subyacentes, como diabetes, hipertensión y enfermedad cardiovascular ${ }^{(16)}$.

Al 30 de enero de 2020, 7734 casos han sido confirmados en China y otros 90 casos también han sido reportados de varios países que incluyen Taiwán, Tailandia, Vietnam, Malasia, Nepal, Sri Lanka, Camboya, Japón, Singapur, República de Corea, Emiratos Árabes Unidos, Estados Unidos, Filipinas, India, Australia, Canadá, Finlandia, Francia y Alemania. La tasa de letalidad se calculó en 2,2 \% (170/7824) ${ }^{(21)}$. El COVID-19 resultó en una mortalidad mucho más baja (aproximadamente 2,67 \% actualizada) entre los casos confirmados, en comparación con el Síndrome Respiratorio Agudo Severo (SRAS) en 9,60\% (noviembre de 2002 - julio de 2003) y el Síndrome Respiratorio del Medio Oriente (MERS) a 34,4\% (abril de 2012 a noviembre de 2019). La mediana de edad para los pacientes de COVID-19, SARS y MERS es de $55.5,41.3$ y 52.8 años, respectivamente. Los pacientes con COVID-19 y MERS comparten una composición de género similar de mujeres (32\%) y hombres (67\%), pero los pacientes con SARS muestran casi la misma proporción de hombres (46,9%) y mujeres $(53,1 \%)^{(22)}$.

La letalidad, según la serie publicada por el CDC Chino con un total de 1023 muertes entre los casos 
confirmados (44 672), la letalidad bruta fue de un 2,3\%. El grupo de edad $\geq 80$ años tuvo la letalidad más alta de todos los reportes de Información científica-técnica. Enfermedad por coronavirus, COVID-19, 26 de marzo de 2020; 16 grupos de edad con $14,8 \%$. Los pacientes que no presentaban comorbilidades tuvieron una tasa de letalidad de $0,9 \%$, frente a los pacientes con comorbilidades que tuvieron tasas mucho más altas: $10,5 \%$ para aquellos con enfermedad cardiovascular, 7,3 \% para diabetes, 6,3\% para enfermedad respiratoria crónica, 6,0 \% para hipertensión y 5,6 \% para el cáncer ${ }^{(23)}$.

\section{En Europa}

Hasta fines de abril, la letalidad media cruda en Europa es de $9,44 \%$ de los casos notificados; aunque hay que tener en cuenta que este cálculo está sujeto a múltiples sesgos de notificación y por las diferentes políticas de realización de pruebas diagnósticas de cada país ${ }^{(24)}$. Del mismo modo, en España, la letalidad con 213435 casos notificados a la Red Nacional de Vigilancia es de $11,49 \%$, cifra que tendrá que ajustarse a lo largo de la epidemia ${ }^{(25)}$. Mediante modelización se ha estimado una letalidad entre los casos hospitalizados sería $14 \%$ (IC 95 \% 3,9-32\%) (53), y en la población general entre 0,3 y $1 \%{ }^{(26)}$.

\section{Coronavirus en América Latina morbilidad, mortalidad y letalidad}

El coronavirus sigue expandiéndose de manera exponencial en todo el Mundo. Hasta el 3 de mayo de 2020 se han confirmado 3435894 casos de infección. Hasta la fecha, se han reportado casos en 212 países, territorios y áreas; notificados en las seis regiones de la OMS (América, Europa, Asia Sudoriental, Mediterráneo Oriental, Pacífico Occidental y África). En América Latina el escenario es aún más complicado, dado que otras enfermedades infecciosas epidémicas que causan fiebre, luchan con sistemas de salud comprometidos, como es el caso del dengue (Perú) y el sarampión ${ }^{(27)}$.
En referencia a la procedencia de los pacientes "casos 0" contagiados por COVID-19 en América Latina. De los 20 países, once fueron importados desde Italia; entre ellos Brasil, Argentina, Bolivia, Cuba El Salvador, Guatemala México, Puerto Rico, República Dominicana y Uruguay. En otros cinco países, Ecuador, Honduras Perú, Panamá y Venezuela, los pacientes "caso 0" fueron procedentes de España; haciendo un total de un $80 \%$ de procedencia de países europeos.

El primer caso reportado por COIV-19 en Chile fue importado por Singapur, de Nueva York (Estados Unidos) para Costa Rica; y para Nicaragua y Paraguay fueron países de América Latina donde importaron COVI-19. Hasta el 3 de mayo de 2020, a nivel de América Latina fueron reportados 271097 casos con COVID-19. Entre estos se habían notificado más de 107780 casos confirmados por COVID-19 en Brasil, (28) el país con mayor número de casos informados (ver figura 2) y el primer caso de América Latina y el Caribe diagnosticado, México, Ecuador, República Dominicana, Argentina, Chile, Colombia, Costa Rica, Perú, Paraguay, Panamá Bolivia, Honduras, Colombia. Por otra parte, los últimos países en confirmar fueron El Salvador y Nicaragua el 18 de Marzo del 2020. Como ha ocurrido en otras áreas, especialmente en Asia, al menos durante las siguientes semanas y meses, probablemente veremos un número significativo de casos en aquellos y países recientemente afectados en esta región, con múltiples implicaciones. El segundo país de América Latina con mayor número de casos fue Perú con $47372^{{ }^{29}}$. Cabe mencionar que América Latina presenta un incremento del índice muy bajo de casos, en comparación del resto del mundo. Sin embargo, es necesario acatar las medidas de prevención necesarias para contrarrestar la propagación del virus. El tercer país con mayor número de casos confirmados fue Ecuador $31881^{(30)}$, seguido México con $24905^{(31)}$; y los países que cuentan con menos de 500 casos son Paraguay, Venezuela y Nicaragua ${ }^{(32,33)}$ (ver figura 1).

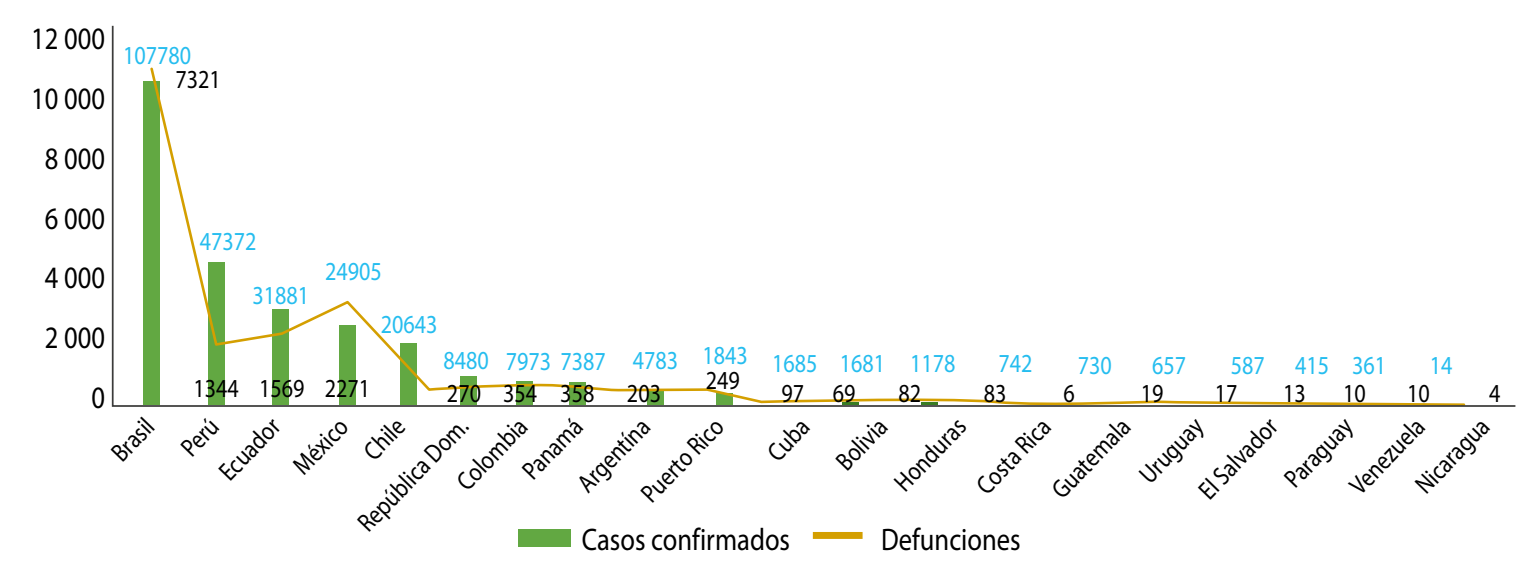

Figura 1. Casos diagnosticados y defunciones por COVID-19 en América Latina (25 Febrero - 3 Mayo de 2020) 
Tabla 1. Tasa de letalidad del COVID-19 en países de América Latina

\begin{tabular}{|c|c|c|c|}
\hline Países & $\begin{array}{c}\text { Casos } \\
\text { diagnosticados }\end{array}$ & Defunciones & $\begin{array}{l}\text { Tasa de } \\
\text { letalidad }\end{array}$ \\
\hline Nicaragua & 14 & 4 & 28,57 \\
\hline México & 24905 & 2271 & 9,12 \\
\hline Honduras & 1178 & 83 & 7,05 \\
\hline Brasil & 107780 & 7321 & 6,79 \\
\hline Puerto Rico & 1843 & 97 & 5,26 \\
\hline Argentina & 4783 & 249 & 5,21 \\
\hline Ecuador & 31881 & 1569 & 4,92 \\
\hline Bolivia & 1681 & 82 & 4,88 \\
\hline Colombia & 7973 & 358 & 4,49 \\
\hline $\begin{array}{l}\text { República } \\
\text { Dominicana }\end{array}$ & 8480 & 354 & 4,17 \\
\hline Cuba & 1685 & 69 & 4,09 \\
\hline Perú & 47372 & 1344 & 2,84 \\
\hline Venezuela & 361 & 10 & 2,77 \\
\hline Panamá & 7387 & 203 & 2,75 \\
\hline Guatemala & 730 & 19 & 2,60 \\
\hline Uruguay & 657 & 17 & 2,59 \\
\hline Paraguay & 415 & 10 & 2,41 \\
\hline El salvador & 587 & 13 & 2,21 \\
\hline Chile & 20643 & 270 & 1,31 \\
\hline \multirow[t]{2}{*}{ Costa Rica } & 742 & 6 & 0,81 \\
\hline & $271097(\Sigma)^{*}$ & $14349(\Sigma)^{*}$ & $5,24(\bar{x})^{* *}$ \\
\hline
\end{tabular}

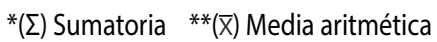

En el Perú fue reportado el primer caso por el presidente del país, Martín Vizcarra, el viernes 6 de marzo del 2020. Este fue un varón de 25 años, trabajador de la empresa LATAM Airlines, quien había recorrido países de Europa, tales como España, Francia y República Checa (34). Así mismo, el 16 de marzo, el presidente de la República decretó el estado de emergencia nacional y la orden de aislamiento social obligatorio, por 56 días $^{(35)}$.
Para el 3 de mayo del presente, en América Latina se presenta 14349 defunciones. Brasil es el país con mayor número de defunciones 7321 , seguido Ecuador con 220, Perú 107; mientras que los países que reportaron un número menor de defunciones son Bolivia, El Salvador, Nicaragua y Uruguay. El promedio de días de producirse las primeras defunciones después de la aparición del primer caso es de 15 días. La tasa de letalidad por COVID-19 coronavirus en América Latina, en general, es de 5,24\%, (14349 muertes/ 271097 casos). Esta tasa es más baja que la observada en otros países como China 5,50 \% (23). Nicaragua es el país con mayor letalidad 28,57 \%, México 9,12\%; seguido por Honduras 7,05\%, Perú 2,84 \%,

El Salvador, Chile y Costa Rica, con menor tasa de letalidad, en $2,21 \%, 1,31 \%$ y 0,81\%, respectivamente (ver tabla 1). Según los datos expuestos en el ver figura 2, los grupos con mayor porcentaje de defunciones (más del $70 \%$ ) por COVID-19 en América Latina, fueron los pacientes mayores de 60 años. Según las investigaciones, este es un considerado un factor para desarrollar de gravedad la enfermedad COVID 19; por lo tanto, la edad sería una variable importante en la gravedad del COVID-19. En Italia, las muertes por COVID-19 se observan principalmente en pacientes varones mayores que también tienen múltiples comorbilidades (ver figura 2).

Con relación a las defunciones por COVID-19, según sexo (ver figura 3), los pacientes varones son la población más vulnerable con un $64,55 \%$ de los casos; debido a que en estos son más comunes la presencia de enfermedades crónicas, en particular las enfermedades cardíacas, la diabetes y el cáncer. Los hombres también están en desventaja por sus bajos niveles de estrógeno, que protegen a las mujeres de muchas enfermedades, incluidas las enfermedades del corazón.

Concluyendo, en base al análisis de nuestros resultados, creemos que las medidas oportunas de prevención y

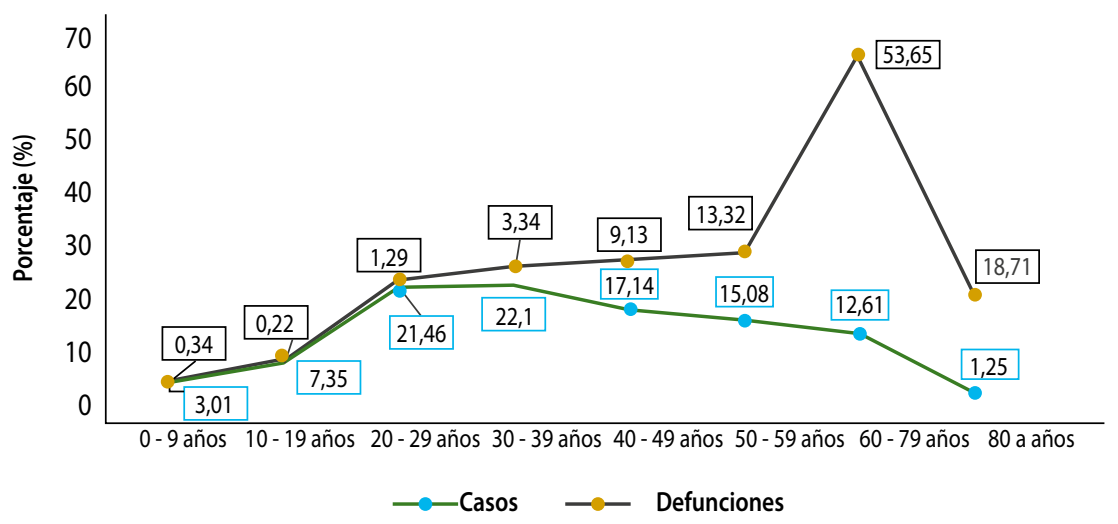

Figura 2. Casos diagnosticados y defunciones por COVID-19, según edad, en América Latina (25 Febrero-3 Mayo de 2020) 


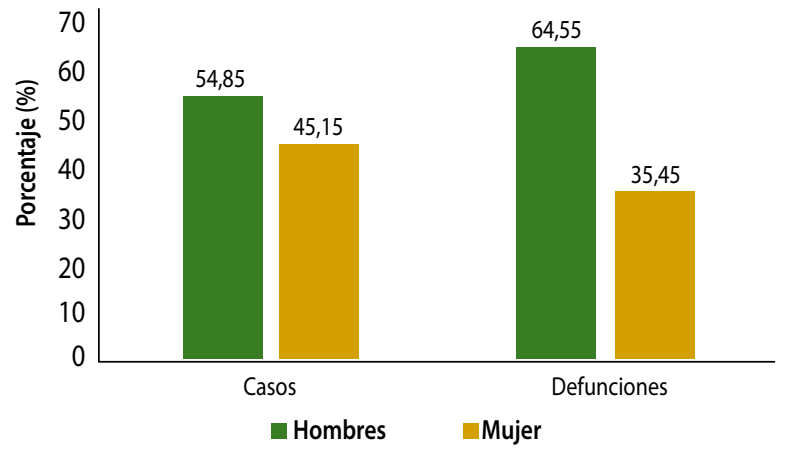

Figura 3. Casos diagnosticados y defunciones por COVID-19 según sexo, en América Latina (25 Febrero-3 Mayo de 2020)

control tomadas por el Estado y los gobiernos, a todos los niveles, han frenado efectivamente la propagación del COVID-19 en China, que todavía plantea un gran desafío para consolidar los resultados del control de la pandemia $y$, finalmente, eliminar la misma. Por lo tanto, el enfoque del próximo paso en el control de epidemias sigue siendo en Italia, España y Estados Unidos. La detección oportuna de las personas infectadas, los pacientes tempranos, el aislamiento y el tratamiento efectivo, son las principales prioridades de las medidas de prevención y control.

Cabe señalar que con la sucesiva apertura de escuelas, la apertura de fábricas y el posterior aumento en la frecuencia de las actividades de reunión de multitudes, el riesgo de transmisión del clúster todavía existe. Hoy, queda mucha incertidumbre aún en torno a la pandemia en curso y cómo se desarrollará en Europa, Estados Unidos y América Latina. Los organismos de salud pública y las instituciones de investigación deben continuar trabajando juntos para evaluar continuamente la situación, abordar las brechas de conocimiento y continuar con la evaluación de la efectividad de las intervenciones específicas con nuevas pruebas, tratamientos y vacunas.

\section{REFERENCIAS BIBLOGRÁFICAS}

1. Gorbalenya A, Baker S, Baric R, de Groot R, Drosten C, Gulyaeva A, et al. Coronavirus agudo severo relacionado con el síndrome respiratorio: la especie y sus virus, una declaración del Grupo de Estudio Coronavirus. Nat Microbiol [Internet] 2020; 5: 536-44 [consultado 2020 Abr 23] Disponible en: https://www.nature.com/ articles/s41564-020-0695-z.pdf

2. Giovanetti $M$, Benvenuto $D$, Angeletti S, Ciccozzi $M$. Los dos primeros casos de 2019-nCoV en Italia: ¿de dónde vienen? J Med Virol [Internet] 2020; 92(5): 518521 [consultado 2020 Abr 22] Disponible en: https:// pubmed.ncbi.nlm.nih.gov/32022275/

3. Paraskevis $D$, Kostaki EG, Magiorkinis G, Panayiotakopoulos G, Sourvinos G, Tsiodras S. El análisis evolutivo de genoma completo del nuevo virus corona (2019-nCoV) rechaza la hipótesis de emergencia como resultado de un evento de recombinación reciente. Infectar Genet Evol [Internet] 2020; 79: 104212 [consultado 2020 Abril 20] Disponible en: https://www.sciencedirect.com/science/article/pii/ S1567134820300447?via\%3Dihub

4. ProMEDmail. PRO/PORT\&gt; Novo coronavírus, COVID-19 - Brasil (11) (SP, ex-Itália), primeiro caso provável ProMEDmail. 20200225.27026525 [Internet] vol.2020. 2020 [Consultado 2020 Abr 22].

5. da Cunha CA, Cimerman S, Weissmann L, Chebabo A, Bellei NCJ. Informativo da Sociedade Brasileira de Infectologia: primeiro caso confirmado de doença pelo novo Coronavírus (COVID-19) no Brasil - 26/02/2020 [Internet] [Consultado 2020 Abr 22] Sao Paulo, Brasil: Sociedade Brasileira de Infectologia; 2020.

6. Biscayart C, Angeleri P, Lloveras S, Chaves T, Schlagenhauf P, Rodriguez A. ¿La próxima gran amenaza para la salud global? Nuevo coronavirus 2019 (2019-nCoV): ¿qué consejo podemos dar a los viajeros? - recomendaciones

7. provisionales de enero de 2020, de la sociedad latinoamericana de medicina del viaje. Respirología. 2018; 23(2): 130-137. doi: 10.1111/resp.13196.

8. Zhong S, Karuppiah T, Suresh K, Guozhong É, Shi V. Factores potenciales que influyen en repetidos brotes de SARS en China. Int. J. Environ. Res. Public Health [Internet] 2020; 17(5), 1633 [consultado 2020 Abr 22] Disponible en: https://doi.org/10.3390/ijerph17051633

9. Lu H, Stratton S, Tang Y. Brote de neumonía de etiología desconocida en Wuhan China: el misterio y el milagro. J. Med. Virol [Internet] 2020; 92(4): 401-402 [consultado 2020 Abr 16] Disponible en: https://onlinelibrary.wiley. com/doi/full/10.1002/jmv.25678

10. Organización Mundial de la Salud: Observaciones del Director General de la OMS en la sesión informativa para los medios sobre 2019-nCoV [consultado $2020 \mathrm{Abr}$ 10] Disponible en: https://www.who.int/dg/speeches/ detail/who-director-general-s-remarks-at-the-mediabriefing-on-2019-ncov-on-11-february-2020

11. Zhu N, Zhang D, Wang W, Li X, Yang B, Song J, et al. Un nuevo coronavirus de pacientes con neumonía en China. N Engl J Med [Internet] 2020; 382(8): 727-733 [consultado $2020 \mathrm{Abr} 15]$ Disponible en: https://www. nejm.org/doi/full/10.1056/NEJMoa2001017

12. Yin $Y$, Wunderink R. MERS, SARS y otros coronavirus como causas de neumonía. Respirología [Internet] 2018; 23(2): 130-137 [consultado 2020 Abr 12] Disponible en: https://pubmed.ncbi.nlm.nih.gov/29052924/

13. Zhou P, Yang X, Wang X, Hu B, Zhang L, Zhang W, Si Hao- $R$, et al. Un brote de neumonía asociado con un nuevo coronavirus de probable origen de murciélago. Naturaleza [Internet] 2020; 579 (7798): 270-273 [consultado 2020 Abr 10] Disponible en: https://doi.org/10.1038/ s41586-020-2012-7

14. Li Q, Guan X, Wu P, Wang X, Zhou L, Tong $Y$, et al. Dinámica de transmisión temprana en wuhan, China, de una nueva neumonía infectada por coronavirus N. Engl. J. Med [Internet] 2020; 382(13): 1199-1207 [consultado 2020 Abr 22] Disponible en: https://www.nejm.org/doi/ full/10.1056/NEJMoa2001316

15. Wang W, Tang J, Wei F. Conocimiento actualizado del brote del nuevo coronavirus 2019 (2019-nCoV) en Wuhan, China J. Med. Virol [Internet] 2020; 92(4): 441447 [consultado 2020 Abr 8] Disponible en: https:// pubmed.ncbi.nlm.nih.gov/31994742/ 
16. Ren LL, Wang $Y$, Wu Z, Xiang $Z$, Guo L, Xu T, et al. Identificación de un nuevo coronavirus que causa neumonía severa en humanos: un estudio descriptivo. Med J (Engl) [Internet] 2020;133(9):1015-1024 [consultado 2020 Abr 15] Disponible en: https://pubmed.ncbi.nlm. nih.gov/32004165/

17. Huang C,WangY, LiX, Ren L,Zhao L, HuY, etal.Características clínicas de pacientes infectados con el nuevo coronavirus 2019 en Wuhan, China Lancet [Internet] 2020; 395(10223): 497-506 [consultado 2020 Abr 9] Disponible en: https:// pubmed.ncbi.nlm.nih.gov/31986264/

18. China. Comisión Nacional de Salud de la República Popular de China y Sistema Nacional de Diagnóstico y Tratamiento de la Medicina Tradicional China para la Neumonía por Coronavirus Novela (Prueba) 6ta Edición [Internet] [consultado $2020 \mathrm{Abr} 10$ ] Disponible en: http://www.nhc.gov.cn/xcs/zhengcwj/202002/8334a8326dd94d329df351d7da8aefc2.shtml

19. Lei J, Li J, Li X, Qi X. Imagen de tomografía computarizada de la nueva neumonía por coronavirus (2019-nCoV) de 2019. Radiología [Internet] 2020; 295(1): 18 [consultado 2020 Abr 14] Disponible en: https://pubmed.ncbi.nlm. nih.gov/32003646/

20. Du Toit A. Brote un nuevo coronavirus. Nat. Rev. Microbiol [Internet] 2020; 18(3): 123 [consultado $2020 \mathrm{Abr} 10$ ] Disponible en: https://doi.org/10.1038/s41579-020-0332-0

21. Grupo de Expertos en Prevención y Control de la Nueva Neumonía por Coronavirus de la Asociación China de Medicina Preventiva. La última comprensión de las características epidemiológicas de la nueva neumonía por coronavirus [J]. Chinese Journal of Epidemiology. 2020; 41: 139-144. DOI: http://doi.or/10.3760/cma.j.is sn.0254-6450.2020.02.002

22. Bassetti M, Vena A, Giacobbe D. Las nuevas infecciones por el coronavirus chino (2019-nCoV): desafíos para combatir la tormenta. EUR. J. Clin. Invest [Internet] 2020; 50(3): e13209. [consultado 2020 Abr 12] Disponible en: https:// pubmed.ncbi.nlm.nih.gov/32003000/?from_term=Basset$\mathrm{ti}+\mathrm{M} \% 2 \mathrm{C}+\mathrm{Vena}+\mathrm{A} \% 2 \mathrm{C}+$ Giacobbe+D.\&from_pos $=4$

23. Deng SQ, Peng H. Características y respuestas de salud pública al brote de la enfermedad por coronavirus 2019 en China. J Clin Med [Internet] 2020; 9(2): 575-584 [consultado 2020 Abr 10] Disponible en: https://pubmed.ncbi.nlm.nih.gov/32093211/?from_term=Publi$c+$ health+characteristics+and+responses+to+the+outbreak+of+coronavirus+disease\&from_pos $=1$

24. OMS. Coronavirus disease (COVID-19) Situation Report105 [Internet] [Consultado 2020 May] Disponible en: https://www.who.int/docs/default-source/coronaviruse/ situation-reports/20200430-sitrep-101-covid-19.pdf?sfvrsn=2ba4e093_2

25. European Center for Disease Control and Prevention Coronavirus disease 2019 (COVID-19) pandemic: increased transmission in the EU/EEA and the UK - seventh update [Internet] [consultado 2020 Mar] Disponible en: https:// www.ecdc.europa.eu/sites/default/files/documents/ RRA-seventh-update-Outbreak-of-coronavirus-disease-COVID-19.pdf
26. European Center for Disease Control and Prevention. Coronavirus disease 2019 (COVID-19) pandemic: increased transmission in the EU/EEA and the UKseventh update [Internet] [Consultado $2020 \mathrm{Mar}$ ] Disponible en: https://www.ecdc.europa.eu/sites/default/ files/documents/RRA-seventh-update-Outbreak-ofcoronavirus-disease-COVID-19.pdf

27. Anderson RM, Heesterbeek $H$, Klinkenberg $D$, Hollingsworth TD. How will country-based mitigation measures influence the course of the COVID-19 epidemic? The Lancet [Internet] 2020; 395(10228): 931934 [consultado 2020 Mar 17] Disponible en: https:// www.thelancet.com/journals/lancet/article/PIIS01406736(20)30567-5/abstract

28. Rodriguez A, Gallego V, Escalera J, Mendez C, Zambrano LI, Franco J, et al. COVID-19 en América Latina: las implicaciones del primer caso confirmado en Brasil. Trav Med Infect Dis [Internet] 2020; 101613 [consultado 2020 Abr 2] Disponible en: https://pubmed.ncbi.nlm.nih.gov/32126292/

29. Brasil. Ministerio da Saúde: Casos de Coronavirus. Brasil: Painel Coronavirus de Brasil [Internet] [Consultado 2020 May 3] Disponible en: https://covid.saude.gov.br/

30. Perú. Ministerio de Salud: Centro Nacional de Epidemiología, Prevención y Control de Enfermedades. Perú. Situación Actual COVID [Internet] [Consultado 2020 May 3] Disponible en: https://www.dge.gob.pe/ portal/docs/tools/coronavirus/coronavirus290420.pdf

31. Ecuador. Ministerio de Salud Pública. Infografía nacional COVID-19 [Internet] [Consultado 2020 May 3] Disponible en: https://www.salud.gob.ec/wp-content/ uploads/2020/05/INFOGRAFIA-NACIONALCOVID19COE-NACIONAL-04052020-08h00.pdf

32. México. Secretaria de Salud. México. Información Oficial COVID-19 | Coronavirus en México [Internet] [Consultado 2020 May 3] Disponible en: https://covid19. sinave.gob.mx/graficastasas.aspx

33. Paraguay. Ministerio de Salud Pública y Bienestar social. Paraguay. Reporde COVID 19. Paraguay [Internet] [Consultado 2020 May 3] Disponible en: https://www. mspbs.gov.py/reporte-covid19.html

34. Venezuela. Ministerio del poder popular para la Salud. Venezuela Boletín Nacional COVID 19 en Venezuela [Internet] [Consultado 2020 May 3] Disponible en: https://covid19.patria.org.ve/estadisticas-venezuela/

35. Ministerio de Salud MINSA. [Internet].Perú. Sala situacional COVID 19. [Consultado 2020 mayo 3]. Disponible en: https://www.gob.pe/institucion/minsa/noticias/111543minsa-casos-confirmados-por-coronavirus-covid-19son-635-en-peru-comunicado-n-36

36. Presidencia de Consejo de Ministros. Internet]. Perú. Decreto Supremo N ${ }^{\circ}$ 046-2020-PCM - Decreto Supremo que precisa el Decreto Supremo $N^{\circ}$ 044-2020-PCM, que declara el Estado de Emergencia Nacional, por las graves circunstancias que afectan la vida de la Nación a consecuencia del brote del COVID 19 Publicado el 18 de marzo de 2020. [Consultado 2020 abril 12]. Disponible en: https://www.gob.pe/institucion/pcm/normaslegales/462244-046-2020-pcm 